GU J Sci, Part C,7(1): 153-164 (2019)

Gazi Üniversitesi

Fen Bilimleri Dergisi

PART C: TASARIM VE TEKNOLOJI

dergipark.gov.tr/http-gujsc-gazi-edu-tr

\title{
Doğrusal Olmayan Yüklerde Güç Faktörünün Düzeltilmesi ve Harmonik Bileșenlerin Süzülmesi
}

\author{
Süleyman $\mathrm{ADAK}^{1,{ }^{*}, \text { Hasan Cangi }}{ }^{2}$, Ahmet SerdarYILMAZ ${ }^{3}$ \\ ${ }^{I}$ Mardin Artuklu Üniversitesi, Meslek Yüksekokulu, Elektrik ve Enerji Bölümü, 47100,Artuklu/MARDİN \\ ${ }^{2,3}$ Kahramanmaraş Sütçü İmam Üniversitesi, Mimarlık Mühendislilik Fakültesi, Elektrik Elektronik Mühendisliği Bölümü, \\ 2018,KAHRAMANMARAŞ
}

\section{Makale Bilgisi \\ Basvuru: $16 / 08 / 2018$ \\ Düzeltme: $24 / 10 / 2018$ \\ Kabul:13/01/2019}

Anahtar Kelimeler

Toplam harmonik

distorsiyonu

Doğrusal olmayanyükler

Pasif süzgeçler

\section{Keywords}

Total harmonic

distortions

Non-linear loads

Passive filters
$\ddot{O ̈ z}$

Toplam harmonik distorsiyonu özellikle güç elektronik ekipman ve doğrusal olmayan yüklerinkullanılmasından sonragüç kalitesinin önemli bir konusu oldu. Elektrik sistemlerinin arızasız ve güvenli bir şekilde çalışabilmesi, akım ve gerilim gibi büyüklüklerin $50 \mathrm{~Hz}$ frekansta ve sinüsoidal formda olmasına bağlıdır. Bununla birlikte bir çok nedenlerden dolayı bu temel büyüklükler sinüsoidal özelliklerini kaybederek sistemde istenmeyen harmonikler oluşmaktadır. Harmonik distorsiyonun azaltılması ve güç faktörününiyileştirilmesi içinpasif filtrelerin kullanılması çokca tercih edilen bir yöntemdir.İncelenen güç sistemi, üç fazlı gerilim kaynağı, güç trafosu, altı darbeli kontrolsüz doğrultucu, pasif filtre ve R-L endüktif yükünden oluşmaktadır.Altı darbeli kontrolsüz bir doğrultucu 5, 7, 11, 13, 17, 19 v.b. gibi akım harmonik bileşenleri üretir.Üç fazlı kontrolsüz doğrultucunun giriş akımı toplam harmonik distorsiyonunu azaltmak için pasif filtre kullanılmıștır. Güç sistemi Matlab/Simulink programı kullanılarak modellenmiştir. Simülasyon sonuçları, hem harmoniklerin elimine edildiğini hem de güç katsayının düzeltildiğini göstermektedir.Pasif filtreler kullanmadan önce güç sistemindeki güç katsayısı 0.6877 ve THD I değeri ise \% 12.71 olarak ölçülmüş idi. Pasif filtreler kullanıldıktan sonra ise sistemdeki güç katsayısı 0.99 ve THDI değeri ise \% 3.591 olarak gerçekleşmiştir.

\section{Filtration of Harmonic Components and Correction Power Factor in Nonlinear Loads}

\begin{abstract}
Total harmonic distortion has become an important subject in power quality, especially afteruse of power electronicequipment and non-linear loads. Working of electricity systems smoothly and safety depends on the foundation of quantities such as current and voltage which are sinusoidal and $50 \mathrm{~Hz}$ frequency. However, these foundation quantities lose their sinusoidal characteristics because of many reasons and this occurs unwanted harmonics in the system.It is a highly preferred methodto use passive filtersfor reduction harmonic and to improve the power factor. The proposed power system is a combination of three-phase voltage supply, power transformer, sixpulse rectifier, passivefilter, and R-L inductive load. A six-pulse uncontrolled rectifier produces 5th, 7th, 11th, 13th, 17th, 19th, etc. current harmonics components. A passive filter is used to reduce the total harmonic distortion of the input current of the three-phase uncontrolled rectifier. Power system is modeled by using Matlab/Simulink program. Simulation results show that both the harmonics are eliminated and the power coefficient is corrected.Before using passive filters the power coefficient was 0.6877 , and the THDI value was measured as $12.71 \%$ in the power system. After using passive filters, the power coefficient was 0.99 and the THDI value was measured as $3.591 \%$ in power system.
\end{abstract}




\section{GİRIŞ (INTRODUCTION)}

Elektrik enerjisinin üretimi iletimi ve dağıtımı esnasında sırasında akım ve gerilimin dalga formunun sinüzoidal formda ve $50 \mathrm{~Hz}$ frekansta olması istenir.Bu koşul kaliteyi belirleyen ana faktörlerden biridir.Bununla birlikte birçok nedenden dolayı bu temel büyüklükler temel özelliklerini kaybederek, sistemde istenmeyen harmoniklerin oluşmasına neden olurlar [1,3]. Bir harmonik "periyodik bir dalganın, temel frekansının tam katı olan bir frekansa sahip sinüs biçimli bileşeni" olarak tanımlanır.Harmonikler, bir elektrik sisteminde temel frekansın bazı tam katlarında ortaya çıkan akımlar ve gerilimler olarak dikkate alınırlar.Güç sisteminin prensip şeması şekil 1'de verilmiştir.

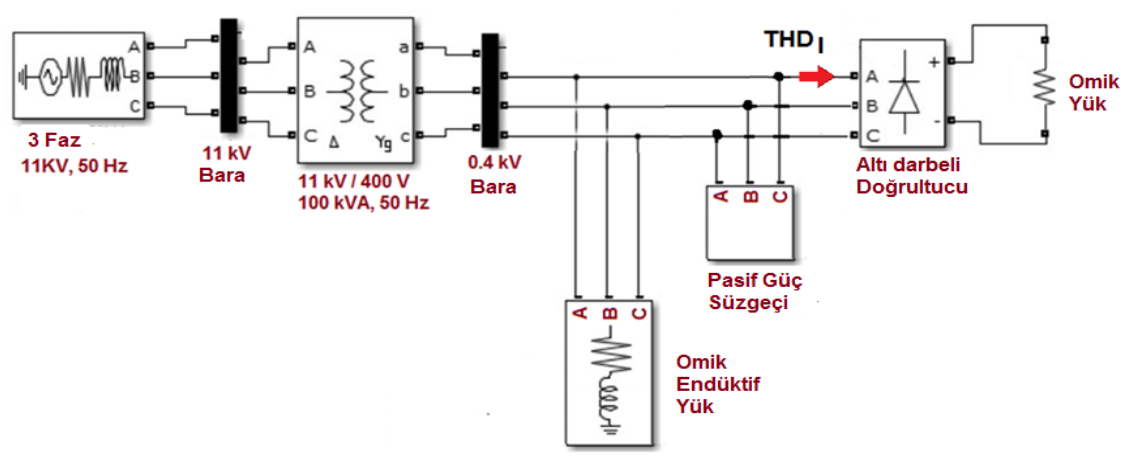

Şekil1.Güç sisteminin prensip şeması

Güç elektroniği tabanlkonvertörler, kıyıcıları ile kesintisiz güç kaynaklarının kullanımının hızla artması ve uygulama alanları nedeniyle, elektrik sistemlerinde gözlenen harmonik distorsiyon giderek artmakta ve bunun sonucunda oluşan harmonik bileşenler enerji kalitesinin düşmesine neden olmaktadırlar.Harmonik distorsiyonudeğerinin yükselmesi işletmedeki cihazlara zarar vermekteve ayrıca sistemdeki kesicilerin zamansız açmalarına, bilgisayarların titreşimli çalışmasına neden olmaktadır.Bir fazlı güç elektroniği tabanlı çihazlar etkin olarak üç ve üçün katı harmonik bileşen üretirler [2, 4].Aydınlatmada kullanılan elektronik balastlı aydınlatma sistemleri ve deşarj tüpleri de önemli bir üçüncü harmonik kaynağıdır.Bir harmonik "periyodik bir dalganın, temel frekansının tam katı olan bir frekansa sahip sinüs biçimli bileşeni”" olarak tanımlanır. Harmonikler,bir elektrik sisteminde temel frekansın bazı tam katlarında ortaya çıkan akımlar ve gerilimler olarak dikkate alınırlar [5, 6]. Harmonik bileşenlerin frekansları,

$$
f_{n}=\text { n. } f_{1}
$$

formülü ile ifade edilir. $\mathrm{Bu}$ ifadede; $\mathrm{n}$ harmonik mertebesini, $\mathrm{f}_{1}$ temel frekans1 göstermektedir. (1) denklemine göre, üçüncü harmonik bileşen, $f_{3}=150 \mathrm{~Hz}$, beşinci harmonik bileşen, $f_{5}=250 \mathrm{~Hz}$ olarak hesaplanır. Alışveriş merkezlerinde ticari binalarda sık, sık karşılaşılan ve tek fazlı ofis cihazlarından kaynaklanan 3 ve 3'ün katı harmonikler nötür hattında devrelerini tamamlarlar.Nötür hattı aşırı ısınır ve ek olarak bu tesislerde nötür-toprak arası gerilimlerin artması sonucu elektronik cihazlarda arızalar oluşmaktadır $[7,9]$. 
Güç sistemlerinde harmonik bileşenlerin elimine edilmesi ile ilgili literatürde bir çok çalışmalar bulunmaktadır. [13] nolu makalede harmonik bileșenlerin aktif ve pasif filtreler ile elimine edilmesi üzerinde çalışılmıştır. [2] nolu ise makalede çok seviyeli inverterde üçüncü harmonik bileşenin enjekte edilmesi ile harmonik analizi gercekleştirilmiştir. Doğrusal olmayankarakteristikli elemanlar güç sistemlerinde ciddi bir harmonik kirliliğe neden olmakta ve tüketiciye verilen enerjinin kalitesini düşürmektedirler.Güç sisteminin güvenilir ve kararlı çalışmasını sağlamak için, tasarım ve işletme aşamasında doğrusal olmayan elemanların veya nonsinüsoidal kaynakların meydana getirdiği harmonik bileşenler hesaplanarak veya ölçülerek ortaya konması vegerekli tedbirlerin alınması gerekir.

\section{PASİF FÍLTRELER VE GÜÇ SİSTEMININ MODELLENMESİ (MODELING OF POWER SYSTEMAND PASSIVE FILTERS)}

Harmoniklerin zararlı etkilerini engellemek için tasarım esnasında bazı önlemler alınır.Bu önlemler yeterli olmayıp harmonic bileşenlerin şebekeye geçmesini engellemek lazımdır.Harmonik bileşenlerin süzülmesini sağlayan devrelere harmonik süzgeçleri denir.Genellikle güç sisteminde etkin harmonik bileşen için hesap yapılır. Etkisi daha az olan harmonik bileşenler için zayıflatan süzgeç devresi tasarlanır.

Pasif filtrelerde amaç yok edilmek istenen harmonik bileşen frekansında rezonansa gelecek $\mathrm{L}$ ve $\mathrm{C}$ değerlerini belirlemektir. Her harmonik bileşen için onu onu rezonansa getirecek ayrı bir süzgeç kolu konulması gerekir.Pasif süzgeçler endüktif ve kapasitif reaktansları birbirine eşit yapan frekansa ayarlanabilir [6, 8].Kalite faktörü Q ayar keskinliğini belirlemektedir.Q faktörüne bağlı olarak süzgeç yada yüksek geçiren yada alçak geçiren tiptedir. Süzgeç hesaplamalarında kompanze edilecek güç formülünden faydalanılır.Güç sisteminde kompanzasyoniçin gerekli reaktif güç değeri;

$$
Q_{\text {Kom }}=\mathrm{P}\left[\tan \left(\cos ^{-1} \varphi_{1}\right)-\tan \left(\cos ^{-1} \varphi_{2}\right)\right]
$$

formula ile bulunur. Burada, $\operatorname{Cos} \varphi_{1}$ kompanzasyon öncesi güç katsayısın1, $\operatorname{Cos} \varphi_{2}$, kompanzasyon sonrası güç katsayısını $\mathrm{P}$, güç sisteminin aktif güçünü göstermektedir. Bulunan bu reaktif gücün pasif süzgeçlere dağılımı;

$$
Q_{f h}=Q_{\text {Kom }} \frac{I_{h}}{\sum I_{h}} \quad h=2,3 \ldots \ldots
$$

formülü ile belirlenir. Burada, $\mathrm{Q}_{\mathrm{fh}}$, $\mathrm{h}$. harmonik bileşene ait reaktif güçü, $\mathrm{Q}_{\text {Kom, güç sisteminde }}$ kompanzasyon için gerekli reaktif gücü, $\mathrm{I}_{\mathrm{h}}$, h. harmonik akım bileşenin genliğini, $\sum I_{h}$, harmonik akımların toplamını göstermektedir. Harmonik büyüklüklerin sınırlandırılmasını amaçlayan harmonik standartlarında çok sıklıkla kullanılan toplam harmonik distorsiyonu, akım için,

$$
\mathrm{THD}_{\mathrm{I}}=\frac{\sqrt{\sum_{n=2}^{\infty} I_{n e f f}^{2}}}{I_{\text {eff }}}
$$

ifadesinden yararlanarak bulunur. Harmonik bileşenlerin efektif değerlerinini, temel bileşen efektif değerine oranıdır [10].Genellikle yüzde olarak ifade edilir.Bu değer doğrusal olmayan dalga formunun sinus dalga formundan sapmasının bir ölçütüdür.Filtreleme öncesi güç sistemine ilişkin prensip şeması Şekil 2.'de verildiği gibidir. 


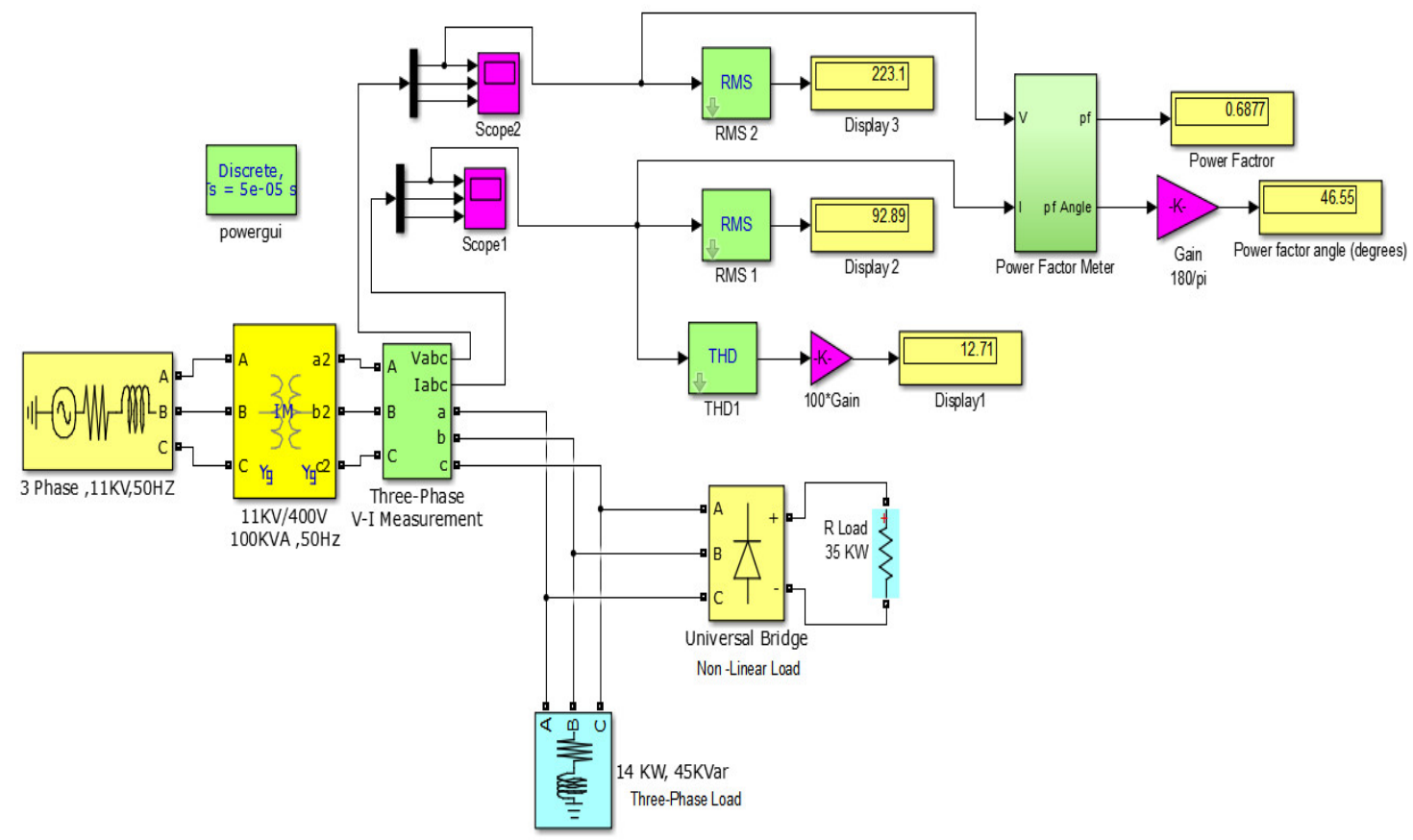

Şekil 2.Güç sisteminin simulink eşdeğeri (filtreleme öncesi)

Harmonik akım ve gerilimlerinin genlikleri mertebesi ile ters orantılıdır, mertebe büyüdükçe harmonik genliği azalır.Harmonik bileşenler akımları harmonik kaynağından, güç sisteminde en düşük empedansa doğru akarlar.Harmonik akım kaynağı tarafından görülen empedans,sistem kaynak empedansı ile sisteme paralel bağlı diğer yüklerin empedanslarıdır.Kısacası sistemdeki tüm elemanları etkilediğinden, harmonikler enerji sistemlerinde istenmeyen niceliklerdir.Non-sinüsoidal dalga biçimleri, periyodik olmakla birlikte sinüsoidal dalga ile frekans ve genliği farklı diğer sinüsoidal dalgaların toplamından oluşmaktadır $[11,15]$.Temel dalga dışındaki sinüzoidal dalgalara "harmonik bileşen" adı verilir. Güç sistemindeki altı darbeli kontrolsüz doğrultucu çıkış gerilimi dalga formu Şekil 3'te verildiği gibidir.

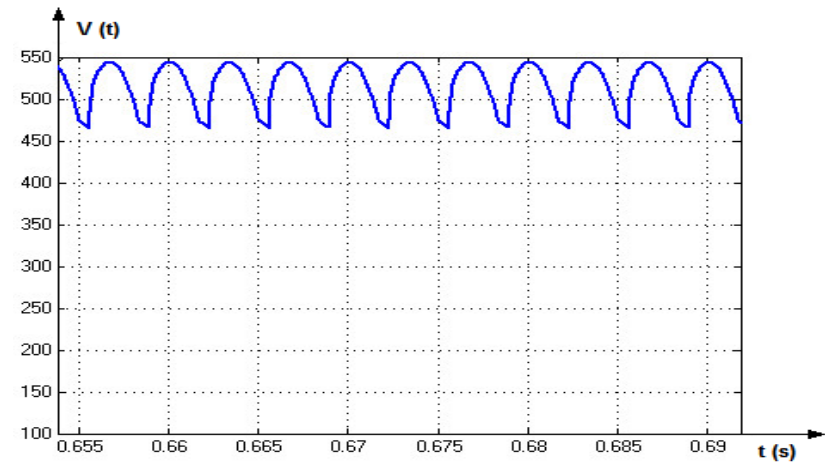

Şekil 3.Altı darbeli doğrultucu çıkış gerilimi

Pasif süzgeçler endüktans, kapasite ve omik dirençten oluşur.Pasif süzgeçler temel bileşen dışındaki harmonik bileşenleri elimine ederler.Kaynak ile yük arasına yerleştirilirler.Elimine edilecek harmonik bileşenlere ait frekans değerinde $\mathrm{L}$ ve $\mathrm{C}$ elemanlarının rezonansa gelmesi sağlanır.Güç sisteminde ki üç fazlı kontrolsüz doğrultucu giriş akımı harmonik bileşenleri genlik ve faz acıları Tablo 1'de verilmiştir. 
Tablo 1.Güç sistemindeki harmonik bileşenler (filtreleme öncesi)

\begin{tabular}{|c|c|c|}
\hline $\begin{array}{c}\text { Harmonik } \\
\text { bileşenler }\end{array}$ & $\begin{array}{c}\text { Harmonik } \\
\text { bileşenlerin } \\
\text { genliği (A) }\end{array}$ & $\begin{array}{c}\text { Harmonik bileşenlerin faz acis1 } \\
\text { (Derece) }\end{array}$ \\
\hline h1 & 130.3 & -48.06 \\
\hline h5 & 13.64 & 145.7 \\
\hline h7 & 6.307 & 118 \\
\hline h11 & 4.949 & -84.74 \\
\hline h13 & 3.039 & -109.4 \\
\hline h17 & 2.571 & 42.17 \\
\hline h19 & 1.66 & 22.9 \\
\hline h23 & 1.426 & 165.3 \\
\hline h25 & 0.9188 & 154.2 \\
\hline h29 & 0.7971 & -78.1 \\
\hline h31 & 0.4823 & -78.09 \\
\hline h35 & 0.4811 & 28.75 \\
\hline h37 & 0.2373 & 37.52 \\
\hline h41 & 0.3555 & 132.3 \\
\hline h43 & 0.1522 & 133.5 \\
\hline h47 & 0.2913 & 118.2 \\
\hline h49 & 0.1473 & -119.7 \\
\hline
\end{tabular}

Doğrusal olmayan karakteristikli yükler düşük güçlü olsalarda güç sistemlerinde sinüsoidal akım ve gerilim dalga formunu bozarlar.Güç sistemlerine bağlanan çok sayıda doğrusal olmayan yükler göz önüne alınırsa bunların sonucunda ek kayıplar ile harmonik bozulma değerlerinin yükselmesine neden olurlar $[12,13]$. Üç fazlı kontrolsüz doğrultucu giriş akımı harmonik bileşenlerinin genliği Şekil 4'te verildiği gibidir.

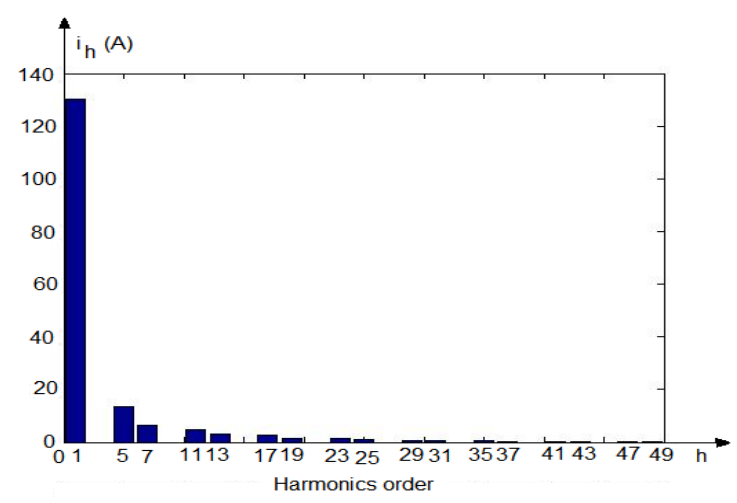

Şekil4.Harmonik bileşenler (filtreleme öncesi)

Süzgeç tasarımı yapılırken düşük dereceli harmonik bileşenler için tek ayarlı süzgeçler kullanılır.Harmonik derecesi büyüdükçe her harmonik bileşen için süzgeç tasarlamak ekonomik olmayacağından yüksek geçiren süzgeç tasarımı ile belirli frekansın üstündeki harmonik bileşenler band geçiren süzgeç ile filtrelenir $[14,17]$.

Kısacası sistemdeki tüm elemanları etkilediğinden, harmonikler enerji sistemlerinde istenmeyen niceliklerdir.Bu yüzden harmonikleri süzecek süzgeç devrelerinin kurulmasına mutlak süratte gerek vardır.Bu sebepten dolayı şebekelere paralel süzgeçler yerleştirilir.Bu paralel süzgeçler içinde bant geçiren ve yüksek geçiren süzgeçler çok sıklıkla kullanılmaktadır $[18,21]$.Bu süzgeçler belirlenen harmonik 
frekansında rezonans oluşturarak harmonikli dalgayı süzerler. Güç transformatörü sekonder akımlarının değişimi Şekil 5 'te verilmiştir.

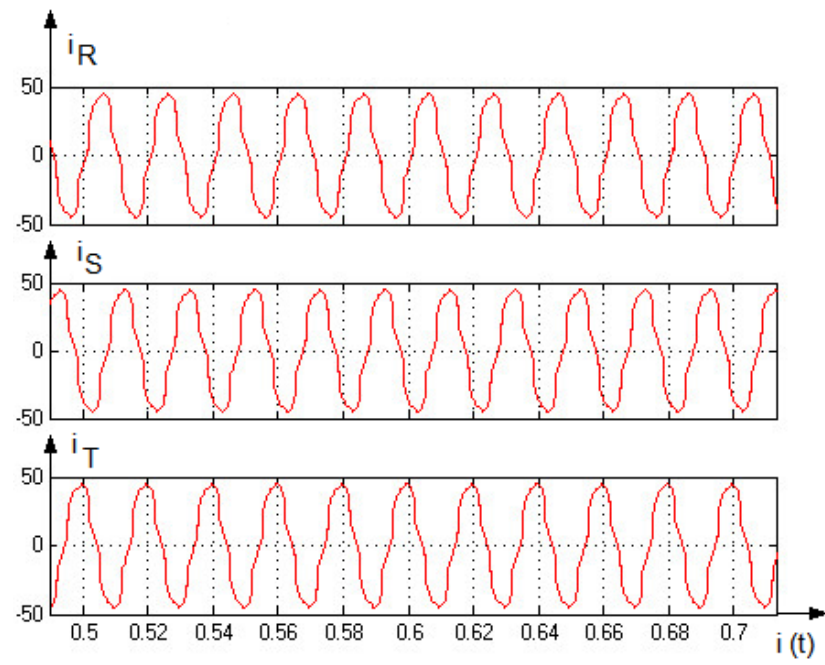

Şekil 5.Güç transformatörü seconder akımı

Doğrusal olmayan yüklerin sebep olduğu harmonik bileşenlerin güç sistemini rezonansa getirmemesine dikkat edilmelidir.Rezonans şartları her harmonik bileşen için ayrı, ayrı hesaplanmalıdır.Bir güç sistemine harmonik kaynaklardan enjekte edilen harmonik bileşenlerin olması durumunda, bunlar şebekedeki herhangi bir bileşen ile rezonans oluşturacak şekilde davranır.Yüksek dereceli harmonik bileşenler, tüm güç sistemini etkileyebilir.Bu etkiler güç sistemi ve diğer ekipmanların da performansını azaltır $[19,20]$.

Güç sistemlerinde tek ayarlı filtre, çift ayarlı filtre ve sönümlü filtrelerkullanılmaktadır.Tek ayarlı filtreler $R$, $L$ ve $C$ parametrelerinden oluşur.Düşük empedans veya kısa devre oluşturarak ayarlanan frekanslardaki harmonik akımlarını süzerler.Çift ayarlı süzgeç adından anlaşılacağı gibi iki ayrı frekansa ayarlı olup ayarlandıkları bu frekanslarda düşük empedans göstererk bu frekanslardaki harmonik bileşenleri süzerler.Sönümlü filtreler ise yüksek mertebeli harmoniklerin filtrelenmesinde kullanılırlar.

\section{HARMONIKLERIN ELIMINASYONU VE GÜÇ KATSAYISININ IYYILEŞTIRILMESI (ELIMINATION OFHARMONICS AND IMPROVEMENT OF POWER FACTOR}

Elektrik enerjisinin üretimi iletimi ve dağıtımı esnasında sırasında akım ve gerilimin sinüzoidal formda ve $50 \mathrm{~Hz}$ frekansta olması istenir.Bu koşul kaliteyi belirleyen ana faktörlerden biridir.Bununla birlikte bir çok nedenden dolayı bu temel büyüklükler temel özelliklerini kaybederek, sistemde harmonik bileşenler oluşmaktadır. Altı darbeli kontrolsüz doğrultucu giriş akımı;

$$
\begin{gathered}
i(\omega t)=130.3 \sin (\omega t-48.06)+13.64 \sin (5 \omega t+145.7)+6.307 \sin (7 \omega t+118)+ \\
4.949 \sin (11 \omega t-84.74)+3.039 \sin (13 \omega t-109.4)+2.571 \sin (17 \omega t+42.17)+ \\
1.66 \sin (19 \omega t+22.9)+1.426 \sin (23 \omega t+165.3)
\end{gathered}
$$

şeklindedir. Bu doğrusal olmayan karakteristikli akım dalgasına ilişkin grafik Şekil 6'da gösterildiği gibidir. 


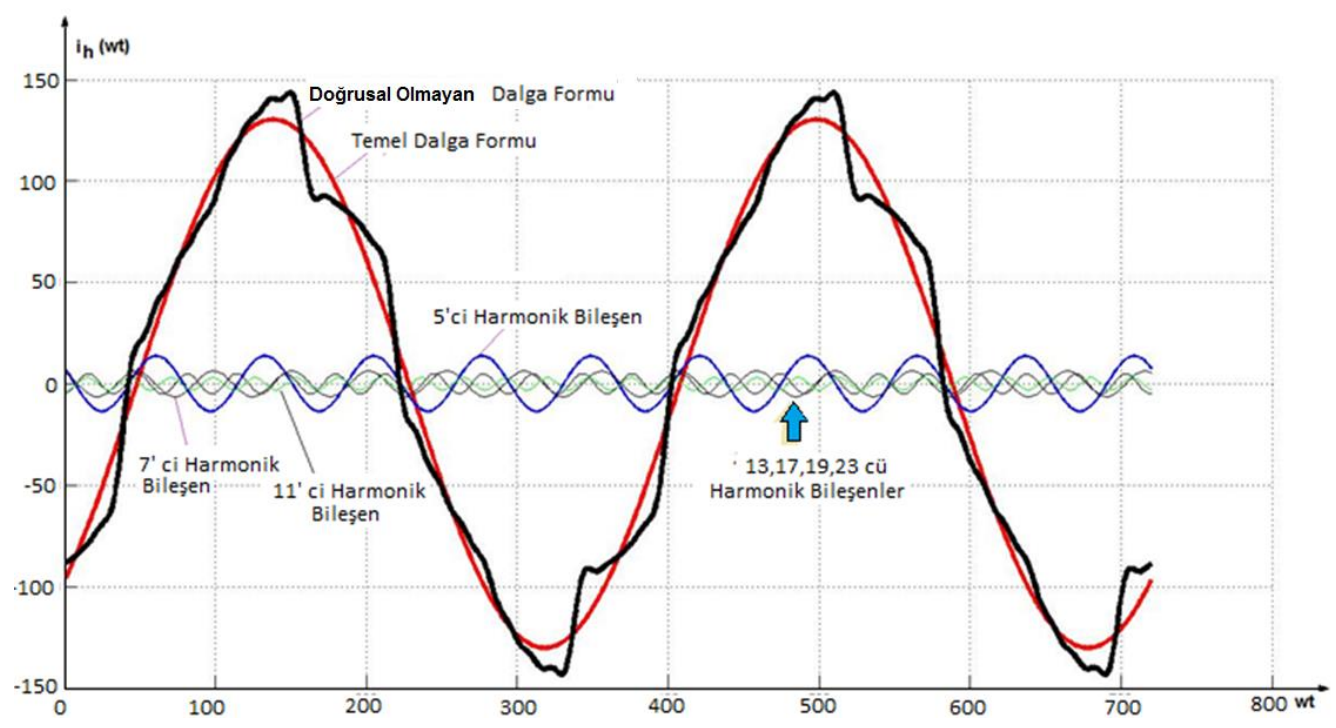

Şekil 6. Doğrusal olmayan dalga formu ile harmonik bileşenleri

Harmonikbileşenleri akımları,harmonik kaynağından, en düşük empedansa doğru akma eğilimindedirler. Harmonik akım kaynağı tarafindan görülen empedans,sistem kaynak empedansı ile sisteme paralel bağlı diğer yüklerin empedansıdır.Kondansatörlerin reaktansı $\mathrm{X}_{\mathrm{C}}$ sistemde harmoniklerin bulunması durumda değeri $\mathrm{X}_{\mathrm{C}} / \mathrm{n}$ olacağından kondansatrörlerde akım değeri oldukça artar ve bundan dolayı, harmonik bileşenlerin etkili olduğu güç sistemlerinde harmoniklerden ençok kondansatörler etkilenir [20].

Enerji kalitesinin yükselmesi için güç sistemlerinde doğrusal olmayan yüklerin etkinliğinin azaltılması gerekir.Bu yüzden harmonikleri süzecek süzgeç devrelerinin kurulmasına mutlak surette gerek vardır.Elektrik tesislerinde harmoniklerin oluşmasının başlıca sebebi, elektrik devrelerinde kullanılan doğrusal olmayan devre elemanlarıdır.Bu devre elemanlarının, gerilimi ile akımı arasındaki bağıntının doğrusal olmasından dolayı harmonik bileşenler oluşmaktadır.Mağnetik devrelerde aşırı doyma elektrik arkları ve güç elektroniği tabanlı devre elemanlarının anahtarlanması ve kıyılması doğrusal olmayan olaylardır.Pasif süzgeçlerle hem güç katsayısı düzeltmesi yapılır hemde reaktif güç kompanzasyonu yapılır. Güç sisteminin filtreleme sonrası prensip şeması Şekil 7'de verilmiştir.

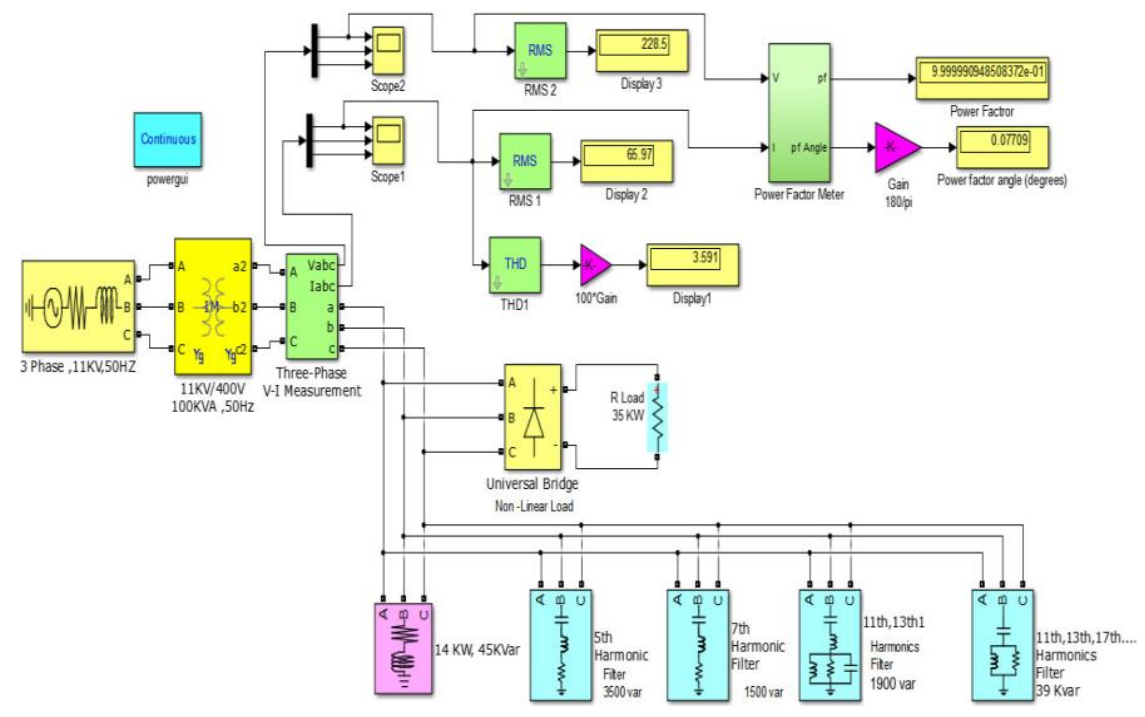

Şekil7. Gü̧ sisteminin simulink eşdeğeri (filtreleme sonrası) 
Aşırı doymuş manyetik devreler, arkla çalışan işletme araçları ile güç elektroniği sistemleri gibi birçok sistemin akımı ile gerilimi arasındaki bağıntı non-liner olduğundan sistemde harmonikler oluşmaktadır. Akım ve gerilimde oluşan bu harmonikler elektrik tesislerine ve bu tesislere bağlı tüketicilere zarar vermekte ve hatta bazen güç sistemlerini çalışamaz hale getirmektedirler. Filtrelemeden sonra üç fazlı kontrolsüz doğrultucu giriş akımı harmonik bileşenlerin genlik ve faz açıları Tablo 2'de verilmiştir.

Tablo 2. Güç sisteminde harmonik bileşenler (filtreleme sonrası)

\begin{tabular}{|c|c|c|}
\hline $\begin{array}{c}\text { Harmonik } \\
\text { bileşenler }\end{array}$ & $\begin{array}{c}\text { Harmonik } \\
\text { bileşenlerin } \\
\text { genliği (A) }\end{array}$ & $\begin{array}{c}\text { Harmonik bileşenlerin faz ac1s1 } \\
\text { (Derece) }\end{array}$ \\
\hline h1 & 93.21 & -2.204 \\
\hline h5 & 2.005 & 82.21 \\
\hline h7 & 1.157 & 87.41 \\
\hline h11 & 0.4829 & -87.78 \\
\hline h13 & 0.2607 & -86.41 \\
\hline h17 & 1.456 & 89.37 \\
\hline h19 & 1.05 & 73.38 \\
\hline h23 & 0.9398 & -125.3 \\
\hline h25 & 0.6944 & -137 \\
\hline h29 & 0.5895 & 20.61 \\
\hline h31 & 0.4517 & 12.39 \\
\hline h35 & 0.3618 & 165.6 \\
\hline h37 & 0.2872 & 160.9 \\
\hline h41 & 0.215 & -51.73 \\
\hline h43 & 0.176 & -52.53 \\
\hline h47 & 0.1244 & 85.92 \\
\hline h49 & 0.103 & 89.92 \\
\hline
\end{tabular}

Harmonikler transformatörlerde bakır ile demir kayıpları ile kaçak akıların artmasına sebep olurlar. Döner elektrik makinelerinde kayma ve momenti etkileyerek gürültü ve titreşimli çalışmaya sebep olurlar.Aynı zamanda sinüs dalgasının sıfırdan geçişine göre tetikleme yapan sistemlerin yanlış sinyaller vermesine neden olurlar.Harmonikler nedeni ile oluşan rezonansolaylarında sistemdeki sigortaların sıksık atmasına, koruma rölelerinin düzensiz çalışmasına ve tüm cihazların ömürlerinin kısalmasına neden olmaktadırlar.Süzgeçleme sonrası üç fazlı kontrolsüz doğrultucu giriş akımı harmonik bileşenlerin genliği Şekil 8'de verildiği gibidir. 


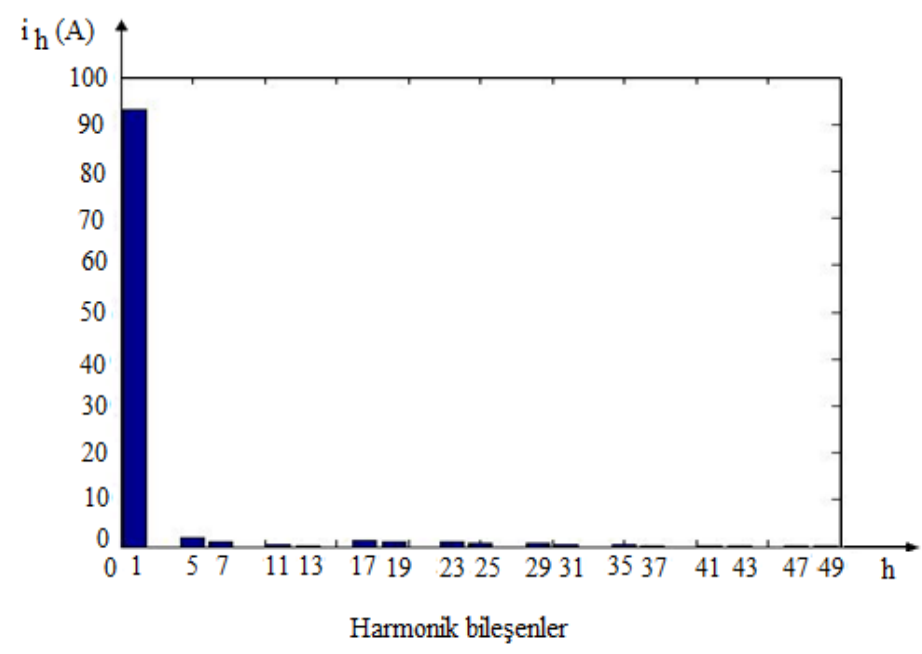

Şekil 8. Güç sistemindeki harmonik bileşenler (filtreleme sonrası)

Şebekede en fazla etkisi görülen harmonikler sırası ile $150 \mathrm{~Hz}$ frekanslı üçüncü harmonik, $250 \mathrm{~Hz}$ frekanslı beşinci harmonik ve $350 \mathrm{~Hz}$ frekanslı yedinci harmoniktir. Üçüncü harmonik bileşen genellikle bir fazlı doğrusal olmayan yükler tarafından üretilir.Doğrusal olmayan yükler tarafından 5.ve 7.harmonik bileşenler üretilir.

\section{SIMMÜLASYON SONUÇLARI (SIMULATION RESULTS)}

Üç fazlı dağıtım sisteminin tek fazlı büyük yükleri beslediği ofislerde ticari binalarda üçüncü harmonik etkin olarak bulunmaktadır.Temel frekanstaki dengeli 3 fazlı akımlar nötür iletkeninde akım oluşturmazlar.Ancak, 3 fazlı sistemlerde 3'lü harmonikler nötür iletkende birbirlerini güçlendirirler.Nötür iletkenleri faz iletkenleriyle aynı boyutlarda olduğundan bu durumda nötür iletkeni aşırı yüklenebilir. Söz konusu soruna karşı alınan en yaygın önlem, nötür iletkeninden geçen akımın hesaplanıp buna göre kesit seçimi yapılması veya üçüncü harmoniği elimine edecek süzgeç yerleştirilmesidir. Güç sistemindeki üç fazlı kontrolsüz doğrultucu giriş akımı harmonik bileşenlerin genlikleri (filtreleme öncesi ve sonrası) değerleri Tablo 3’te verilmiştir. 
Tablo 3.Güç sisteminde harmonik bileşenler (filtreleme öncesi ve sonrası)

\begin{tabular}{|c|c|c|}
\hline $\begin{array}{c}\text { Harmonik } \\
\text { bileşenler }\end{array}$ & $\begin{array}{c}\text { Harmonik } \\
\text { bileşenlerin } \\
\text { genliği } \\
\text { (Süzgeçleme } \\
\text { öncesi) (A) }\end{array}$ & $\begin{array}{c}\text { Harmonik bileşenlerin genliği } \\
\text { (Süzgeçleme sonras1) (A) }\end{array}$ \\
\hline h1 & 130.3 & 93.21 \\
\hline h5 & 13.64 & 2.005 \\
\hline h7 & 6.307 & 1.157 \\
\hline h11 & 4.949 & 0.4829 \\
\hline h13 & 3.039 & 0.2607 \\
\hline h17 & 2.571 & 1.456 \\
\hline h19 & 1.66 & 1.05 \\
\hline h23 & 1.426 & 0.9398 \\
\hline h25 & 0.9188 & 0.6944 \\
\hline h29 & 0.7971 & 0.5895 \\
\hline h31 & 0.4823 & 0.4517 \\
\hline h35 & 0.4811 & 0.3618 \\
\hline h37 & 0.2373 & 0.2872 \\
\hline h41 & 0.3555 & 0.215 \\
\hline h43 & 0.1522 & 0.176 \\
\hline h47 & 0.2913 & 0.1244 \\
\hline h49 & 0.1473 & 0.103 \\
\hline & & \\
\hline
\end{tabular}

Harmoniklerin enerji sistemindeki teknik ve ekonomik olumsuzluklarının giderilmesi bakımından birtakım önlemlerin alınması gerekir.Enerji sisteminin tasarımından sonraki safhada harmonik bozulmanın istenen sınır değerlerin altına düşürülmesinde için harmonik filtre devrelerinin kullanılması gerekmektedir.Üç fazlı kontrolsüz doğrultucu giriş akımı harmonik bileşenlerin genlikleri (filtreleme öncesi ve sonrası) Şekil 9'da verildiği gibidir. 


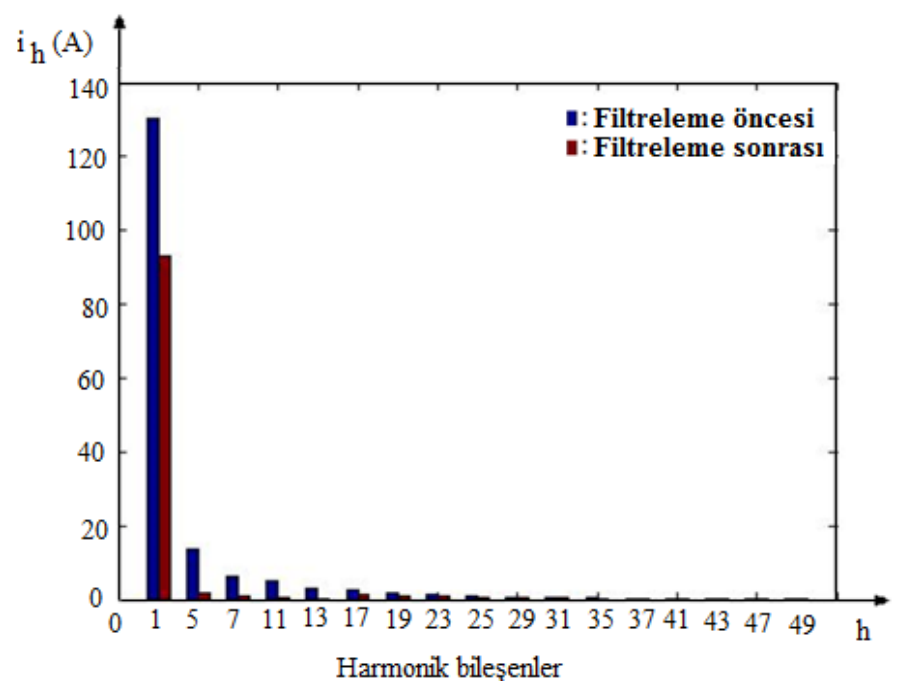

Şekil 9.Kontrolsüz doğrultucu giriş akımıharmonik bileşenleri

Güç sistemdeki harmonik bileşenler ek 1sı kayıplarına neden olmaktadırlar.Bu ek kayıp enerji maliyetini artırmaktadır.Ayrıca sistem üzerindeki temel harmonik dışındaki harmonik bileşenler ek gerilim düşümleri oluşturmaktadır.Elektrik tesisleride ağırlıklı olarak ofis akipmanları, kesintisiz güç kaynakları ile gaz deşajlı lambalar üçüncü harmonik bileşen üretirler.Mümkün mertebe bu cihazların üç fazlısı seçilmelidir.Üç ve üçün katı harmonikler üç fazlı konvertörlerde sıfırdır.

\section{SONUÇLAR (CONCLUSIONS)}

Güç elektroniği elemanları ve çeşitli doğrusal olmayan elemanların her gecen gün artış göstermesi enerji sisteminde dolaşan non-sinüsoidal büyüklüklerin artmasına neden olmaktadırlar.Bunun bir sonucu, akım yada gerilim için harmonik distorsiyonu da artmaktadır.Elektrik güç sistemlerinde harmonik distorsiyon sıklıkla orijinal kaynaklardan büyük uzaklıkta bulunan mesafelerde tüm sistemi etkilemektedir.Harmonikler güç sistemlerindeki kirliliktir. Statik dönüştürücülerin kullanımının artması ile bu kirlilik oranı gün be gün artmaktadır

Pasif süzgeçler kaynak ile yük arasına bağlanırlar.Temel frekans dışındaki harmonik bileşenleri yok ederler.Seri bağlı kondansatör ve endüktansın bileşiminden oluşurlar. Bazı durumlarda omik direnç elemanı da bağlanabilir.Güç sisteminde harmonik bileşenlerinisüzgeçlemek için 2 adet tek ayarlısüzgeç, 1 adet çift ayarlı süzgeç ve 1 adet ikinci dereceden sönümlü süzgeç kullanılmıştır.

Güç sisteminde filtre kullanmadan önce güç faktörü 0.6877 ve toplam harmonik distorsiyonu \%12.71 olarak ölçülmüştür.Güç sisteminde pasif filtrelerkullanılması ile güç faktörü 0.99 ve toplam harmonik distorsiyonu ise \%3.591 olarak gerçekleşmiştir.

\section{KAYNAKLAR (REFERENCES)}

[1] Dastfan, A., Yassami H. and Rafiei M. R., Optimum Design of Passive Harmonic Filter by Using Game Theory Concepts.Intelligent Systems in Electrical Engineering, Vol. 4, No. 4.2014.

[2] Çolak, İ., Bayindir, R. and Kabalci, E., A Modified Harmonic Mitigation Analysis Using Third Harmonic Injection PWM in a Multilevel Inverter Control, 14th International Power Electronics and Motion Control Conference Ohrid, Macedonia, 2010.

[3] Germeç, K. E., Erdem H., Time-harmonic analysis in electric power systems, Journal of the Faculty of Engineering and Architecture of Gazi University, 30 (2), 263-271, 2015.

[4] Bayindir, R. Sağiroğlu, Ş. Çolak, İ. Alper Ö., Investigating Industrial Risks Based on Information Security for Observerable Electrical Energy Distribution System and Suggestions. Journal of the Faculty of Engineering and Architecture of Gazi University, 24(34)(715-723). 2009.

[5] Rashid, H.M., Power Electronics, Circuits, Devices, and Applications, Perason Press, 2014. 
[6] Adak, S., Cangi, H., Analysis and Simulation Total Harmonic Distortion of Output Voltage Three Level Diode Clamped Inverter in Photovoltaic System, Bitlis Eren University, Fen Bilimleri Dergisi, ISSN 2147-3129,2015.

[7] Kocatepe, C., Uzunoglu, M., Yumurtac1, R. ve Arıkan, O., Elektrik Tesislerinde Harmonikler, Birsen Yayınevi, İstanbul 2003.

[8] Bhende,CN. Kalam,A. Malla,SG., Mitigation of Power Quality Problems in Grid-Interactive Distributed Generation System, DE Gruyter:International Journal of Emerging Electric Power Systems, Vol. 17, pp. 165-172, April 2016.

[9] Ozdemir, A. Ferikoglu, A., Low cost mixed-signal microcontroller based power measurement technique - IEE Proceedings-Science Measurement And Technology - Vol.151 - pp.253-258 - ISSN : 1350-2344 - DOI : 10.1049/ip-smt:20040242 - JUL - - Article - - 2004 - WOS:000222969400004.

[10]Yilmaz, A. S., Alkan, A. and H. Asyali, M., Applications of parametric spectral estimation methods on detection of power system harmonics, Electric Power Systems Research, 78, Issue 4, , pp 683-693, April 2008.

[11] Rüstemli, S., Okuducu, E., Efe, S.B., Elektrik Tesislerinde Harmoniklerin Pasif Filtre Kullanılarak Azaltılması ve Simülasyonu, EVK2015: 6. 2015, Enerji Verimliliği Kalitesi Sempozyumu, pp120-124, 4-6 Haziran, Sakarya.

[12]Memon, Z. A., Uquaili, M. A. and Unar, M. A., Harmonics mitigation of industrial power system using passive filters.Mehran University Research Journal of Engineering and Technology, Vol. 31, No. 2, pp. 355-360, 2012.

[13] Hideaki, F., Hirohmi, A., A Practical Approach to Harmonic Compensation in Power Systems-Series Connection of Passive and Active Filters, IEEE Transactions On Industry Applications, Vol. 21, No. 6, 1991.

[14]Ayan, K. Arifoğlu, U., Optimizing reactive power flow of HVDC systems using genetic algorithm International Journal of Electrical Power \& Energy Systems - Vol.55 - pp.1-12 - ISSN : 0142-0615 DOI : 10.1016/j.ijepes.2013.

[15]Anooja C. L. and Leena N., Passive Filter for Harmonic Mitigation of Power Diode Rectifier and SCR Rectifier Fed Loads. International Journal of Scientific \& Engineering Research, Vol. 4, No. 6, 2013.

[16]Adak,S., Mitigation Harmonic with LCL Passive Filter in off-Grid PV SystemJournal of Engineering and Tecnology, 2;1, pp. 9-20, 2018.

[17] Sekkeli, M., Tarkan N., Development of a novel method for optimal use of a newly designed reactive power control relay. International Journal of Electrical Power and Energy Systems 2013; 44:736-742.

[18] Srivastava, K. K., Shakil S. and Pandey A. V., Harmonics \& Its Mitigation Technique by Passive Shunt Filter. International Journal of Soft Computing and Engineering (IJSCE) ISSN, pp. 2231-2307, 2013.

[19]Çetin, S., Veri Merkezi Uygulamaları için Yüksek Verimli Bir LLC Rezonanslı DC-DC Dönüştürücü Tasarımı, GU J Sci, Part C, 5(1): 45-54, 2017.

[20] Özçira, S., Aktif Güç Filtre Tipinin Kompanze Edilmesi Gereken Büyüklüğe Göre Belirlenmesi GU J Sci, Part C, 6(3): 691-704, 2018. 